\title{
Organization Development Experiences - A Case for Enriching HRD through OD
}

\author{
T.V. Rao
}

W.P. No. 2010 - 01 - 01

January 2010

The main objective of the working paper series of the IIMA is to help faculty members, research staff and doctoral students to speedily share their research findings with professional colleagues and test their research findings at the pre-publication stage. IIMA is committed to maintain academic freedom. The opinion(s), view(s) and conclusion(s) expressed in the working paper are those of the authors and not that of IIMA.

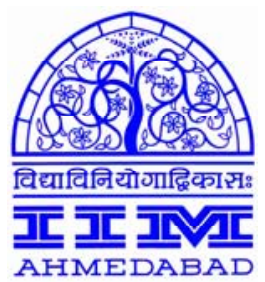

INDIAN INSTITUTE OF MANAGEMENT

AHMEDABAD-380 015

INDIA 


\title{
Organization Development Experiences - A Case for Enriching HRD through OD
}

\author{
T.V. Rao \\ Professor \\ Indian Institute of Management, Ahmedabad \\ Email: tvrao@tvrao.com, tvrao@iimahd.ernet.in
}

\begin{abstract}
This article reviews a few definitions of $O D$ and identifies eight characters that are necessary to call an activity or experience as an $O D$ activity or experience. The article then goes on to examine ten case studies (of research, consulting and OD) of what appears like an OD activity in which the author was involved as one of the facilitators for whole system or subsystem and examines each on of them for their appropriateness to be called as $\mathrm{OD}$ interventions. The author then goes on to derive some lessons from these experiences. The article outlines also some advantages of using traditional OD approach in various HRD interventions and offers some suggestions for making specific HRD interventions like competency mapping, 360Degree Feedback based leadership Development and Assessment and Development Centers as OD activities. The paper concludes that using an OD approach enriches HRD and yields a good ROI on HRD interventions.
\end{abstract}




\section{Organization Development Experiences - A Case for Enriching HRD through OD}

\section{Organization Development}

"Building on a sound research base from the behavioural sciences, OD started in the 60s with great promise. From the early Hawthorne studies and then expanded by the work of Argyris, French, McGregor, Likert, Marrow, Maslow and others OD appeared to open up an entirely new way to produce change and to manage organizations." (Bradford, 2005 p xxiii)

OD went International and had many success stories in 60s, 70s and 80s.

"But those heady days appeared to have passed. Even though the number of people who call themselves as "OD Consultants" has continued to increase, they are rarely in the top layers of the organizations. Instead, if they exist at all within the institution, they are relegated far down in the bowels of the organization, usually being a part of HR (not the highest status area itself). CEOs rarely Call in OD consultants and instead rely on the major consulting firms, many of which have taken on the rhetoric (if not the practice) of the OD field. OD consultants may be brought inn, but usually for small ventures- a team building activity, a "visioning" experience at some retreat, perhaps some personal coaching, but rarely the system wide interventions that occurred before" (Bradford, 2005, in Foreword to the book on "Practicing Organization development by Rothwell and Sullivan, 2005, p xxv).

Bradford concludes that there are four factors that seem to play a major role in the declined centrality of OD:

1. Few of those who call themselves OD consultants are really doing OD! Few of those who use techniques developed by OD are not doing real OD which involves a comprehensive systems approach to planned change.

2. There is no ' $\mathrm{O}$ ' in OD.

3. There is no integrating theory of change.

4. OD is confused about its values. OD has lost its commitment to rigorous objective analysis of what truly is effective and instead replaced it with a view of what it thinks that the world should be.

\section{Definitions of OD}

"An effort planned organization wide, and managed from the top, to increase organizational effectiveness and health through planned interventions in the organizations’ processes using behavioral science knowledge”. (Beckhard, 1969) 
“ OD is a planned effort, initiated by process specialists to help an organization develop its diagnostic skills, coping capabilities, linkage strategies in the form of temporary and semi-permanent systems and a culture of mutuality” ( Pareek, 1975)

"OD is a systematic effort, using behavioral science knowledge and skill, to change or transform the organization to a new state”. (Beckhard, 1999)

Some of the other definitions as cited in Rothwell and Sullivan (2005, see the article by Warrick, pages 167-169) are given below:

OD ". is a response to change, a complex educational strategy intended to change the beliefs, attitudes, values, and structure of organization so that they can better adapt to new technologies, markets, and challenges, and the dizzying rate of change itself" (Bennis, 1969)

“ OD is a system-wide and value based collaborative process of applying behavioural science knowledge to the adaptive development, improvement, and reinforcement of such organizational features as the strategies, structures, processes, people, and cultures that lead to organizational effectiveness” (Bradford, Burke, Seashore and Worley, 2004 as quoted by Warrick, 2005)

OD...”is a long term effort, led and supported by top management, to improve organization's visioning, empowerment, learning, and problem solving processes, through an ongoing, collaborative management of organization culture with special emphasis on the culture of intact work teams and other team configurations-using the consultant facilitator t $\backslash$ role and the theory and technology of applied behavioral science including action research” (French and Bell, 1999)

After examining a lot of definitions Warrick (2005) has offered the following definition: "OD is a planned and collaborative process for understanding, developing, and changing organizations to improve their health, effectiveness and wolf renewing capabilities” (Warrick, 2005, p 172).

The most frequently mentioned definition of OD is by Richard Beckhard which stood the test of time (Warrick, 2005 p 168).

\section{What qualifies and Activity or Experience to be classified as an OD activity or experience?}

Warrick (2005) from his research on OD identified the following 13 characteristics and 15 values of OD:

Characteristics of OD (Warrick, 2005)

1. Recognizes what you change and how you change as equally important and emphasizes health, effectiveness, and adaptability of an organization.

2. OD can be used with all sizes of organizations and at all levels of an organization. 
3. Recognizes the dynamic process of change and that change takes time and quick fix solutions rarely last.

4. Approaches change from systems or big picture perspective and considers interrelatedness of various systems and components.

5. OD is an interdisciplinary approach and draws heavily from behavioural science knowledge.

6. OD is data driven.

7. OD uses action research process and involves key stake holders.

8. OD is typically facilitated by professionally trained change agents who believe in helping others to discover solutions to their own issues than dictating what should be done.

9. OD is a value driven approach that seeks to instill values and build cultures that bring out the best in people.

10. OD is collaborative top down and bottom up process.

11. OD is an education based strategy.

12. OD is committed to transference of knowledge and skills

13. OD emphasizes the importance of reliable feedback in monitoring and managing the change process.

\section{OD values}

1. Development

2. Professionalism

3. Helping people and organizations

4. Respect to all individuals

5. Inclusion, collaboration and participation

6. Open, honest and candid communications

7. Authenticity

8. Inquiry

9. Community

10. Diversity

11. Personal and organization awareness, growth and learning

12. Experimentation

13. Creating a realistic hope

14. Integrity

15. Confidentiality

In the light of this recent study by Warrick Udai Pareek's eight values as OD values OCTAPACE seem to take care of most of these values. (Openness, Collaboration, Trust, Authenticity, Proactivity, Autonomy, Confrontation, and experimentation). These values were subsequently incorporated by the author to develop a HRD Prayer (Rao, 2003)

In the light of the above and from a review of various articles on OD and our own past work ( see Udai Pareek, 1975 and Ramnarayan, Rao and Singh, 1998) the following eight characteristics have been identified to qualify and activity or experience to be an 
OD experience. The term activity or experience is used here to represent all the series of interventions undertaken by the consultant while working with an organization or its sub system to bring our any change or improvements.

\section{What qualifies to be an OD Intervention?}

1. It should be planned (unplanned activities and problem solving efforts are not OD).

2. It follows a sequential process. Burke (1982) presented eight steps of entry; start up, diagnosis or assessment and feedback, action planning, interventions, evaluation including an assessment of change and improvements, adoption and separation or disengagement.

3. It should be long term. Short term interventions, one time activities and specific time bound tasks or problem solving experiences by them selves are not OD.

4. It should aim at the whole organization. The organization may be sub unit within the unit but the whole of it must be dealt with. Tinkering with small unit of a unit can not be considered as OD. Can improvements in delegation by the top management through a task force be considered OD? The answer is No. the same may be considered as OD if it is initiated by a specialist

5. Should start form the top. This ensures seriousness and implementation.

6. Should be based on Behavioural science knowledge. Should be collaborative effort between the organization and the facilitator (external or internal)

7. Should be value based - OCTAPACE or something similar

8. Aim at improvements in the organization which means change, effectiveness, vision any one or more aspects of the organization functioning

The list can be expanded, but these seem to be essentials emerging from various approaches and definitions.

\section{An Evaluation of Some activities and Experiences: Are they really OD Experiences?}

In this part of the paper I wish to take a few experiments and Interventions we have made in the last thirty years and examine which of them are classified as OD interventions and which of them are not with reasons. I then proceed to argue that OD should be revitalized and reinvented with its original rigor and commitment. I also wish to conclude that not all HD Interventions are OD interventions. However there is scope to use HRD interventions in an OD framework and make them more useful than before. Most of the experiences mentioned below did not start under the label as OD experiences or projects. However one or more of the consultants involved in each of these experiences are trained OD consultants and strong believers of OD values (OCTAPACE). Some of them in retrospect could be called as OD experiences while the others even if they carried the label of OD may not qualify to be OD experiences. First each of these ten projects is briefly described and they are followed by a table of evaluation using the above mentioned criteria. 


\section{Changing teacher Behavior through Observational feedback:}

This was a three year project conceived and completed by Dr Udai Pareek and sponsored by the Indian Council of Medical research and carried out at the national Institute of health Administration and Education in late sixties and early seventies. I had the privilege of working in this project. In this project we fist established the linkage between the classroom behaviour of teachers and their student mental health. We found that directive teachers produced certain type of adjustment and personality while no directive teachers have been found to be associated with more adjusted, imitative taking, and positive mental $\backslash l$ health tlstudents. We then observed the teachers in the classroom using a large number of observers trained in classroom interaction analysis. We then invited the primary schools teachers for a feedback program where they were taught the observations technique and its applications and their curiosity to know their own interaction patterns were aroused, we then gave them feedback and latter observed them in the classroom to see if there is any behavior changer. The results revealed that the teachers did change dramatically on the basis of the feedback they received thought he education system did not require them to change. (Facilitators: Udai Pareek, T. V. Rao, Prabha Ramalingaswamy, B R Sharma, K G Agarwal, and many other observers)

\section{Changing health worker behavior through feedback and self renewal: An Experiment of Worker Client transactions in Uttar Pradesh}

In its eagerness to improve health systems in India Government of India has chosen UP as one of the steps to professionalize management and invited the IIMA to work with the government of UP and professionalize management in six of the districts of Uttar Pradesh. An interdisciplinary team of consultants from IIMA worked on this project for nearly five years. As a part of this project the transactions and influence patterns of family planning and health workers in two primary health centers of Sulatanpur district (Amethi and Kurebhar) were studied by trained observers accompanying them to villages and observing their actual education, informational and influence processes. They were then called for a renewal workshop where they were trained to look at their own transaction patterns and examine the implications. Their transactions were linked with their performance. They also shared with ach other their philosophy and practice. They were then given feedback of their behavior and were helped to set goals for change. Subsequent evaluation indicated some change on the part of the health workers.

(Behavioural sciences part lead by $\mathrm{T}$ V Rao, as a part of a large Interdisciplinary team including J K Satia, V K Gupta, Nirmala Murthy, M. N. Vora and others from IIMA)

\section{Designing and Introducing HRD in a large systems:}

In this started s a review of the performance appraisal system for managers evolved into the designing of a HRD system including a number of subsystems and resulted in starting of a new function called HRD function. The project lasted for nearly three eyras and was implemented through a series of task forces internally managed and implemented. The 
consultants worked as facilitators and assisted the internal team in establishing the new department, clarifying its functions, and assisted in implementing systems. In five years time all the mangers were trained in the new systems and the new HRD function was well established and internalized. The interventions involved workshops, meetings, education sessions, internal reviews etc. The intervention was repeated in many other organizations with marginal changes learning from the process implemented in the fist organization and adapting to the unique needs of other organizations. (Consultants: Udai Pareek and T V Rao)

\section{Self renewal of a School System (Lawrence school Sanawar, and Doon School, Dehradun):}

The principal of a school contacted one of the consultants that everything is so smooth in his school he finds it difficult to believe everything is so excellent. The consultant visited the school and identified overdependence of the Head Master as an issue and the faculty are losing initiative as result of their admiration for the head of the Institution. U\it was decided to conduct a self renewal laboratory for the entire school, staff covering all the teachers. The self renewal alb lasted for about five days when the school climate was measured and areas for improvement identified. The renewal included role negotiating exercises between the school teachers, principal, Head of departments, house masters etc. and resulted in identification of a number of areas of improvement. The task forces were established to improve various subsystems of the school like the teaching learning process, tutorial system etc. The task forces worked for over a year and brought changes in some of the systems. A similar experiment $\mathrm{n}$ was repeated in Doon school a bout fifteen years alter and the faculty were helped to examine the purpose and strategy of the school. New systems were initiated. The work ended as a one time experiment.

(Facilitators: Ravi J Matthai, Udai Pareek and T V Rao for Sanawar and Udai Pareek and T V Rao for Dun School)

\section{Organizational Climate Survey feedback to build Team culture in a company:}

The Vice Chairman of a company observed that in spite of his repeated efforts to build them as a team the various unit heads of his conglomerate are not Seeing Eye to eye and are working in various directions. His monthly management team meetings have resulted in show down by some of his Directors, and discussion of small matters like dress code, tea breaks etc, rather than substantial business mat It was felt that units with various cultures need to collaborate, work like a team, think together and align with each other as there are a lot of business synergies between them. A climate survey to bring out similarities and differences among the various units and using it for discussion may result in more working together. The consultant was introduced as a HRD consultant to survey the organization climate and give feedback of the survey. The consultant went round meeting various heads and their managers. The consultant had meetings with cross section of managers to discuss areas of concern to be included in the survey. A hundred item questionnaires was developed and finalized with the help of the top team. The 
survey was administered to all employees and anonymous data were conducted surveying their perceptions of the organization climate. The data were presented in two day top management meet which aimed at examining the data and preparing action plans to improve the status. The workshop resulted in their thinking together, discovering common issues, and preparing action plans to improve. The workshop also resulted in a series of role negotiation exercises and more structuring of the future meetings. Subsequent to the team building workshop some structural changes were initiated and the meetings were redesigned. The consultant withdrew after the team building workshop. The intervention lasted across six months. Many changes were made to improve the efficiency and effectiveness of the team working and various other HR issues. The CEO used the survey data to initiate many changes in the system. The CEO went round presenting the data along with his top team and used it to initiate changes. (Consultant: $\mathrm{T}$. V. Rao)

\section{Restructuring of Bank of Baroda:}

We were asked to examine the branch level reorganization of Bank of Baroda. This involved a year long project examining the organizational structure at all levels except the HO. The project resulted in recommendations for transfer pricing, creation of new roles, suggested reorganization of regional and zonal offices etc. A number of recommendations were implemented but the consultants were not even involved in the implementation. The recommendations dealt with training, performance appraisal and many other systems besides a new organizational structure. The experience was successful. (Consultants Involved: NR Sheath, V Govindarajan and T. V. Rao)

A similar restructuring was one of the National Institute of Educational Administration and Education at New Delhi. The project lasted d for over six months. The methodology included setting of the terms of reference along with the faculty of the Institute. Participative methodology was used. Internal task forces and teams were used. A number of things suggested were implemented by the faculty themselves without even waiting for the formal initiation of the processes by the Ministry of Education as the faculty were involved in the discussions etc. Only structural changes were made subsequently by the Government. (People Involved: Author, UNESCO representative, Ministry representative, internal members of the Institution)

\section{Bringing Process Sensitivity to build problem solving, team work and other capabilities in a construction Company:}

The company wanted to grow and develop its own internal process sensitivity, initiative, and problem solving capabilities. A consultant was brought in. Initial diagnosis was done using participative methods involving the top team. The top team then collected more information on many issues. They identified some of the issues like lack of rewards, lack of accountability, team work, performance planning and development and appreciation of each other. It was decided to meet every quarter for two days to become more process sensitive after a five day T-group intervention. The group continued to meet every quarter 
for the next five years or so during which period several of them sent their juniors for sensitivity training or process labs by ISABS, conducted role analysis and clarity exercises, redesigned their appraisal system and made many other interventions. Over the next few years the meetings continued and the organization is considered as having robust processes and interpersonal sensitivity and internal problem solving capabilities. Even after the CEO changed the new CEOs who were largely from within valued this experience and continued the same. The changing of the Performance appraisal system and introduction of the new incentive system was an outcome of these interventions though other consultants were called in for specific projects. (People involved: Somnath Chattopadhyay, Udai Pareek, and Deepankar Roy. The author was involved in redesigning the PMS and participating in select workshops to share findings and)

\section{Professionalizing management in the Health system of a country through various interventions- HTRD Project Indonesia:}

The Ministry of Health wanted to professionalism its management, this involved the professionalizing and training of health administrators in several of the provinces (like Indian states), the Institutions and also changing the mind set of all employees at the National, Provincial, District and block level health functionaries. The project started with sample tasks analysis and demonstration of the use of task analysis. It them resulted in extending the task analysis to hospitals, provincial health services and developing inhouse capabilities in task analysis and developing various professional management systems using the results. The system developed include identification of training needs, redesigning training programs, capacity building of the Health administrators and other officials, institution building of National health Institute, developing case studies and case development and internal training capabilities etc. The intervention lasted over four years and Experts were stationed at site for this period. It resulted in a high degree of professionalisation of the Management and administration of health systems in Indonesia. (People involved: Rolf Lynton, Ronnie Lynton, Udai Pareek, Michael Merrill, author and many other short term consultants from the USA. The author was involved for a period of two years for doing task analysis work and demonstrating its utility for designing various HR systems)

\section{Process Consultation for an International Conference (ICM Sisters):}

ICM is a congregation based in Rome with heavy presence in India and with the objective of helping the poor in terms of education, health, self employment of the poor, women and physically challenged. The congregation has its presence in a number of countries and faced a number of issues like the differing nature and commitment of the new entrant who were joining the organization. They did not all speak the same language. The process consultation focused on the sisters working for a month to re-examine their structure, systems and processes and particularly focusing on the bahviour the young sisters and the top management styles. The initial exercises were designed to create OCTAPACE culture in the conference. This was done through micro lab and various exercises and game. The movement from unfreezing to interventions and refreezing was 
planned by the consultants. The first day initiation through a micro lab created open culture and enabled them to discuss freely and frankly all their views and hare reflections. Prayers were combined with exercises around meaningful themes. This aimed at creating a facilitating climate for discussions and focused on creation of OCTAPAC values for discussion. The Indian team was subsequently helped to examine the same issues across a period of two years. (Facilitators: Udai Pareek and T V Rao)

\section{Introducing Performance Appraisal in SAIL:}

SAIL approached two consultants from IIMA to assist in designing and implementing a performance appraisal system. The PAS was identified as one of the systems to change as a part of the priorities for action initiative. An internal team designed a preliminary appraisals system after going through the current system and its deficiencies. The consultants studied the system and suggested marginal changes and got approval to change it further through a process of testing it out on internal managers. The change was introduced through a series of workshops to prepare internal resource persons. The internal resources persons were prepared to assist in implementation. Their roles lasted for over three year period. They assisted in preparing manuals and sensing the implementation needs and failures and suggesting corrective action. Over three eyras period the system was introduced and stabilized the reward and promotions systems were revamped and the output used for recognizing good performers. The system brought in role clarity, improving the training system and brought in improved accountabilities though not to a satisfactory level. The system was revised after four years and changes made incorporating the suggestions of Ivarious stake holders. The system lasted for the next ten years or more. (Consultants; Arun Monappa, T. V Rao and Udai Pareek)

\section{Evaluation of the often interventions as to their suitability to be called as OD Interventions.}

The table given below presents and evaluation of the ten interventions against the eight criteria mentioned earlier to be qualified as an OD intervention.

\begin{tabular}{|l|l|}
\hline Intervention & Whether it meets the criteria of OD and if not reasons \\
\hline $\begin{array}{l}\text { 1. Changing teacher } \\
\text { feedback } \\
\text { through }\end{array}$ & $\begin{array}{l}\text { This does not qualify to be called an OD intervention. There is no } \\
\text { organization involved. It is an experiment and research. Behaviour } \\
\text { change occurred. Such studies generate knowledge for OD interventions } \\
\text { but are not OD interventions in themselves. } \\
\text { If the Education department or a schools or the set of schools were } \\
\text { involved and their top management got committed and change sustained } \\
\text { it would have been OD intervention. This is at best an action research. } \\
\text { Such researches while lay foundation for change are not OD } \\
\text { interventions themselves as they are not sustained. }\end{array}$ \\
\hline
\end{tabular}




\begin{tabular}{|c|c|}
\hline $\begin{array}{l}\text { 2. Changing health } \\
\text { worker behaviour } \\
\text { through feedback and } \\
\text { self renewal }\end{array}$ & $\begin{array}{l}\text { Top management involved. Government of UP and Govt of India. } \\
\text { Behavioural science knowledge used only in select projects } \\
\text { Participative value or culture is used only at the intervention stage and } \\
\text { not in planning and implementing change. Only a part of the system was } \\
\text { involved } \\
\text { Change was planned, Sequential process followed in the experiment. } \\
\text { Survey feedback (observational) and human process laboratory to } \\
\text { improve interpersonal communications were used. } \\
\text { Aimed at health worker effectiveness and resulted in change in short } \\
\text { term but may not have been sustained. No institutionalization of change } \\
\text { Long term. Lasted over a year } \\
\text { Collaborative effort with behavioural science facilitator } \\
\text { Cannot be strictly called OD as it never became a part of the } \\
\text { system. At best his is also action research and not OD. }\end{array}$ \\
\hline $\begin{array}{l}\text { 3. Designing and } \\
\text { Introducing HRD in a } \\
\text { large system }\end{array}$ & $\begin{array}{l}\text { Top management involved } \\
\text { Behavioural science knowledge used } \\
\text { Participative value or culture used. } \\
\text { Whole system involved } \\
\text { Change was planned, Sequential process followed. } \\
\text { Many interventions used: Task forces, training, developing internal } \\
\text { resources, survey feedback etc. } \\
\text { Aimed at organizational effectiveness and resulted in change } \\
\text { Long term } \\
\text { Collaborative effort with behavioural science facilitator } \\
\text { This turns out to be an OD experience in retrospect though it did } \\
\text { not start as an OD intervention. The facilitators used perhaps even } \\
\text { without their knowledge this as an OD effort. }\end{array}$ \\
\hline $\begin{array}{l}\text { 4. Self renewal of a } \\
\text { school system, }\end{array}$ & $\begin{array}{l}\text { Top management involved } \\
\text { Behavioural science knowledge used } \\
\text { Participative value or culture used. } \\
\text { Whole system involved } \\
\text { Change was planned, Sequential process followed. } \\
\text { Many interventions used: Task forces, self renewal workshop, role } \\
\text { negotiations, training, survey feedback etc. } \\
\text { Aimed at organizational effectiveness and resulted in change } \\
\text { Lasted over an year } \\
\text { Collaborative effort with behavioural science facilitator. } \\
\text { This is clearly a short term OD experience. While Lawrence School } \\
\text { Sanawar is a clear OD the Doon School experience only uses an OD } \\
\text { intervention and does not qualify to be called as OD. No long term } \\
\text { work and facilitators came intervened and within the interventions } \\
\text { followed OD principles but not followed the sequential process etc. }\end{array}$ \\
\hline
\end{tabular}




\begin{tabular}{|c|c|}
\hline $\begin{array}{l}\text { 5. Organization } \\
\text { climate surveys and } \\
\text { survey feedback of a } \\
\text { company }\end{array}$ & $\begin{array}{l}\text { Top management involved } \\
\text { Behavioural science knowledge used } \\
\text { Participative value or culture used. } \\
\text { Whole system involved } \\
\text { Change was planned, Sequential process followed. } \\
\text { Interventions used include survey feedback and team building } \\
\text { workshop. } \\
\text { Aimed at organizational effectiveness and resulted in change } \\
\text { Not very long term as facilitator withdrew after the team building } \\
\text { workshop } \\
\text { Collaborative effort with behavioural science facilitator } \\
\text { This qualifies to be an OD experience }\end{array}$ \\
\hline $\begin{array}{l}\text { 6. Reorganizing a } \\
\text { Bank }\end{array}$ & $\begin{array}{l}\text { This is a mere restructuring. All organizational restructuring does not } \\
\text { qualify to be OD. However a large part of sequential process is followed } \\
\text { but consultants withdrew after submitting their report and they were not } \\
\text { used to implement any interventions. } \\
\text { Assuming that the Bank has implemented some change without } \\
\text { adequate knowledge of the change and the way it has been driven it } \\
\text { becomes difficult to call this an OD intervention. It had the potential to } \\
\text { be an OD intervention if the top management followed up in a planned } \\
\text { way and managed change. } \\
\text { Lack of continuity in implementation is what takes this away from } \\
\text { being called an OD intervention. }\end{array}$ \\
\hline $\begin{array}{l}\text { 7. Bringing process } \\
\text { sensitivity in a } \\
\text { construction industry }\end{array}$ & $\begin{array}{l}\text { Top management involved } \\
\text { Behavioural science knowledge used } \\
\text { Participative value or culture used. } \\
\text { Whole system involved } \\
\text { Change was planned. Sequential process followed. } \\
\text { Many interventions used: Task forces, training, developing internal } \\
\text { resources, survey feedback etc. } \\
\text { Aimed at organizational effectiveness and resulted in change } \\
\text { Long term } \\
\text { Collaborative effort with behavioural science facilitator. } \\
\text { This is the most effective example of an OD intervention. The } \\
\text { facilitator followed all the principles of OD and continued for a long } \\
\text { time. } \\
\text { Only question mark if any may have been in relation to disengagement } \\
\text { of one of the consultants who continued for a long time almost giving an } \\
\text { impression that he has becomes a part of the organization. }\end{array}$ \\
\hline
\end{tabular}




\begin{tabular}{|c|c|}
\hline $\begin{array}{l}\text { 8. Professionalizing } \\
\text { management in the } \\
\text { Health system of a } \\
\text { country through } \\
\text { various interventions }\end{array}$ & $\begin{array}{l}\text { Top management involved. Ministry of Health. } \\
\text { Behavioural science knowledge used } \\
\text { Participative value or culture used. } \\
\text { Whole system involved } \\
\text { Change was planned, Sequential process followed. } \\
\text { Many interventions used: Task analysis workshops, training, developing } \\
\text { internal resources, internal resources trained etc. } \\
\text { Aimed at organizational effectiveness and resulted in change } \\
\text { Long term } \\
\text { Collaborative effort with behavioural science facilitators } \\
\text { This has all the qualities of along term OD experience. }\end{array}$ \\
\hline $\begin{array}{l}\text { 9. Process consultation } \\
\text { for an International } \\
\text { conference }\end{array}$ & $\begin{array}{l}\text { Top management involved. } \\
\text { Behavioural science knowledge used } \\
\text { Participative value or culture used. } \\
\text { Whole system involved } \\
\text { Change was planned, Sequential process followed. } \\
\text { Many interventions used: Task forces, training, developing internal } \\
\text { resources, survey feedback etc. } \\
\text { Aimed at organizational effectiveness and resulted in change } \\
\text { Intervention lasted for a few days though the consultants were called } \\
\text { once in a while for follow up activities. } \\
\text { Collaborative effort with behavioral science facilitator } \\
\text { Though this is limited to a conference it qualifies to be called OD as } \\
\text { it meets most requirements except the long term involvement. }\end{array}$ \\
\hline $\begin{array}{l}\text { 10. Introducing } \\
\text { Performance Appraisal } \\
\text { in SAIL }\end{array}$ & $\begin{array}{l}\text { Top management involved } \\
\text { Behavioural science knowledge used } \\
\text { Participative value or culture used. } \\
\text { Whole system involved } \\
\text { Change was planned, Sequential process followed. } \\
\text { Many interventions used: Task forces, training, developing internal } \\
\text { resources, survey feedback etc. } \\
\text { Aimed at organizational effectiveness and resulted in change } \\
\text { Long term } \\
\text { Collaborative effort with behavioural science facilitator } \\
\text { This qualifies to be an OD experience though this dealt with the } \\
\text { introduction of a subsystem. It affected all managers and used } \\
\text { participative process and is highly value driven. }\end{array}$ \\
\hline
\end{tabular}




\section{What is the advantage of making an Intervention or Experience as an OD Intervention?}

The above discussion indicates that a strictly OD experience is likely to give better RROI than a one time intervention. Now days as observed by Bradford in his Foreword, organizations are increasingly using consultants to carry out specific interventions to either develop vision, or change their performance appraisal system, to study employee engagement or to develop fast trackers etc. Win all these interventions while there may be positive results the sustainability of the quick fixes is always an issue,. For an effective execution and ROI the above analysis indicates that a long term involvement of behavioral specialist trained in change management process will go a long way in getting sustainable advantage to the company.

In view of this one may examine number of HRD interventions and see how they could be made as OD interventions to maximize their value.

Use of an OD approach and values is highly recommended for getting the maximum benefit from some of the interventions.

Six interventions usually undertaken by most management consultants are taken and analyzed for using an OD approach to maximize the ROI.

These include:

1. Competency mapping exercises

2. Leadership development programs using 360 Degree Feedback and climate surveys

3. Assessment and development centers

4. Performance appraisal interventions

5. Survey feedback interventions

6. Employee engagement surveys

Of these the last two are age old interventions using survey feedback method. The first four are explained in some detail.

\section{How does one make specific HRD Interventions to be OD Interventions?}

Now a days large number of corporations are using a variety of HR interventions. The interventions are likely to yield a good ROI if they are converted into an OD approach. See for example a good illustration of the condition under which executive coaching can give a good return on investment the article by Joy McGovern, et al (2001) who point out that coaching can have maximum impact when the coaches are selected carefully, provided strong organizational support for the program, impact is measured and feedback is given and is widely made available. While the authors do not promote it as OD their suggestion use very much an OD framework. The author of this article believes that using an OD framework or attempting use an OD approach in mot change management interventions will help a great deal in enhancing ROI for HRD Interventions. 


\section{ODification of HRD: How to get the best from HRD Interventions using an OD approach to them?}

\section{Competency mapping: How to make it an OD intervention}

Map the competencies for the entire organization. Use participative process. Use facilitators to initiate the exercise. This intervention needs specialists in behavioural science. Ascertain the qualifications of the facilitator. The facilitator should have skills in identifying knowledge attitudes, skills, and knowledge of competency mapping techniques. The competency mapping bys itself is a participative process. When mapped and the competencies are used for organization wide interventions it becomes an OD intervention. If you just map the competencies for a few roles and produce a report and do nothing about is an OD intervention. Competency mapping and designing competency based HR systems is one of the most ROI giving interventions if taken to logical end. By virtue of its linkages with other HR systems it is a whole system involving exercise.

1. Start from the top. Top management should know the purpose and importance of CM. They should be involved in setting the vision and strategic plan.

2. Use Behavioural science specialists and knowledge. CM has nearly sixty years of work starting with the work of Benjamin Bloom and team. Unless educationists trained in CM are used it may be hijacked into other directions.

3. Use sequential approach. CM should start with diagnosis. What is lacking because of lack of role directory, role clarity, team work, capability shortage, succession planning? What a right diagnosis can help? Use participative approach. Develop internal resource. Explain the importance of CM to all levels. Disengage after competency based HR systems one in place.

4. Use multiple interventions, workshops, seminars; interviews, task forces etc. conduct it for all levels.

5. Demonstrate how it leads to organizational effectiveness and change. Link it with all other systems - recruitment, induction, PMS etc. such an approach has been explained in detailed by competency mapping manuals by TVRLS. (TVRLS, 2006)

\section{OD approach to Performance Management System (PMS)}

PMS is a great change tool. This has been recognized in India in mid seventies by organizations like Larsen and Toubro. Some experiences narrated above deal with this. However most organization treat it merely as a system to manage people or as a human resource management system than as a change management system. The potential of this tool has been grossly underestimated and attention paid to this and investments made on this are extremely small. The most important investment it requires is a managerial time. The even this time is a mere $1 \%$ to $5 \%$ of each manager's time in a year to plan, review, 
and develop the performance, competencies and culture of individuals, dyads, teams and the organization as a whole.

1. Understand the potential of PMS. This may be done by the top management and all strategically important individuals or managers sitting together and subjecting themselves to a learning session a by examining how organizations across the world have used PMS as a change tool.

2. Examine the multiple objectives of PMS and choose the objectives that are manageable in a short span and in the long run.

3. Conduct diagnostic studies of why PM Systems (or performance appraisal systems) have not worked in the past. The author has given elsewhere details of the reasons behind the failure of the performance appraisal and management systems (See for details: "Performance Management: from Systems to spiritual approach” in Rao, 2004 and also Rao, 2008).

4. Use a participative approach. Get top management commitment. Help them to experience how it helps them focus their work, plan time and maximize their impact.

5. PMS facilitator should be knowledgeable in behavioral sciences. The person should be process sensitive, know goal setting, identify Key Performance Areas KPAs, difference between KPAs \& KRAs (Key result Areas), force field analysis, coaching, biases in ratings etc.

6. The interventions may include education program, training internal resource persons etc.

7. There should be periodic surveys and survey feedback a on the system and its implementation. Most often the in-house teams need to do a lot of work in the process of suing PMS as a change management tool.

A good PMS can create new culture of transparence, integrity, and promote OCTAPACE values mentioned earlier. The intervention should be system driven and should involve the whole system.

\section{Leadership Development using 360 Degree Feedback}

A number of organization use leadership development in-house based on the 360 Degree feedback. The usual design is to start with a competency framework and develop a leadership and managerial effectiveness tool. This tool is then used to get individual assessments made for the top level, senior level and middle level executives. 360 Degree feedback profiles are prepared based on the assessments of juniors, seniors, internal and external customers of the candidate along with self assessment. The assessments are summarized and graphically presented to help the candidate get an insight into his/her own behavior and leadership competencies. The profiles are then given to the candidates individually and perhaps in a workshop form. The candidates are then assisted to prepare action palms and make commitments to change. The level-wise (HOD, General Manager, Vice-presidents etc.) or the group-wise trends of the feedback are shared and development activities undertaken by the HR department. For example if most 
participants need to be vision driven or systems driven then a series of programs to develop their vision or systems orientation are made and a training intervention undertaken. Individual coaching also becomes part of the intervention.

To conduct a 360 Degree feedback and make it an OD activity:

1. Start with company-wide education or expose the entire SBU or the levels in the hierarchy.

2. Develop the tool on the basis of participative methodology and catering the needs of the organization. Incorporate company values and priorities.

3. Get top involvement as $360 \mathrm{DF}$ involves high time investments. Use sequential process.

4. Use a "Facilitator" for this purpose. Some of the "360 Facilitators" are vendors of 360 tools. What you need is a 360 Facilitator and not a tool vendor. Do not use facilitators that have not been trained in Behavioral Science Technology and are mere tool vendors. Change can not be bought in an organization through tenders and vendors recruited through tenders. Those who use tenders and vendors are may be doing business with change but can't manage change. The process of giving feedback to the candidate is very critical in a 360 based leadership development program. This can be given only by "process-sensitive” people.

5. The $360 \mathrm{DF}$ should result in an action plan.

6. The action plans can be shared and integrated into the existing systems of PMS through KPAs.

7. Change should be measured and promoted across the company. This can be done through planning and implementing follow up activities. There could be periodic meetings of the 360 teams (teams that have undergone the feedback intervention) and experiences shared. The top management should be brought in to listen to the presentations after a 360 Feedback workshop and also in the follow-up sessions.

8. The 360 DF should result in enhanced awareness of individual to his competencies and competency gap.

9. The intervention could be closed after three to four sittings and integrated into the organizations PMS or training and other systems.

10. Organize training and other intervention to maximize the impact of 360 . Disengagement should happen only after heightened awareness. Appoint executive coaches and mentors to bring it to a logical conclusion.

A good 360 Based leadership program can develop many more leaders and prepare a leadership pipeline in the organization. It can also uplift the level of leadership initiatives and create leadership culture in the organization.

\section{Assessment and Development Centers (ADCs):}

ADCs have begun as potential assessment tools. Over a period of time they have acquired the potential as competency building tools. They are being used for identifying high fliers, succession planning and promotion tools. Though they are tools with limited purpose they can be used for larger purposes including culture change. However, when 
they are used for larger purposes they should be used as culture building tools. Creating a competency culture, high performance culture, leadership culture are some of the higher goals. However they should be supplemented with other interventions like climate surveys, succession planning etc. The limitations of ADCs as predictive tools should be explained. Organizations like Aditya Birla Group in private sector in NTPC, HPCL etc. in public sector have used these interventions to bring systematic changes. Most organizations however make the mistake of frequently changing consultants. Mostly they bring Consultants for specific interventions and as a result synergistic effect is lost. Some consultants are also shy of getting into long term contracts to bring change. Short term interventions have better remuneration possibilities for consultants but may have a limited impact. To make ADCs as OD interventions:

1. Begin with an education program through put the company. This could be done internally. Complete the education process for all those who are going to participate and are going to be affected by the ADCs in some form or the other.

2. Choose your facilitators carefully. The facilitators should not be mere assessors trained in ADCs but should be behavioral scientists committed to change and change management specialists. They should be willing to have a long term commitment (A three to five year period) to work with the organizations.

3. Involve as many internal assessors as possible in ADCs. Train internal assessors.

4. Look for low cost tools and develop indigenous tools than suing borrowed tools tested out $\mathrm{n}$ other culture. Managerial behavior and behavior management is highly culture specific. Borrowed tools help the tool developers and not the users. Cultural change can be brought in with culture sensitive tools.

5. Explain the tools (role plays, in-baskets, simulation games etc.) along with the scores to those who undergo the ADCs.

6. Transfer the tool to the in-house training programs and develop candidates to exhibit behaviors desired and master the tools. This will require frequent changes in the tools.

7. Get each candidate to prepare action plans (called as Individual development Plans or IDPs and similar names) at the end of the ADC.

8. Keep reviewing the implementation by conducting anonymous surveys.

The ultimate success of an ADC is when an ADC can be designed and conducted internally by any organization. Another important indicator of success is the level of improvement in competencies of the candidates who go through the program and the speed with which you can incorporate the tools into your training program and train your people. ADCs are great tools to uplift the competency levels of the organization.

\section{Competencies of an OD Facilitator:}

Normally some behavioural Science education is prescribed for OD facilitator. Normally any Masters degree holder in psychology, sociology, social work, philosophy, human resources management is passed as a Behavioural Scientist. Those who have an MBA can 
be considered BS Trainers provided they have studied personality theories, applied behavioural science dealing with individual, team and organizational psychology and have an understanding of human behavior in organizational settings.

OD is data based. OD specialist should be research driven. It is highly recommended that those who aspire to be OD specialists should strive to the following:

A. Do their Ph.D or equivalent of research course to acquire and demonstrate data based research capabilities.

B. Subscribe to and strive to proactive values particularly OCTAPACE or participative values with authenticity, trustworthiness and integrity. Committed to change and change management.

C. Acquire BS knowledge through ISABS or similar certification programs on coaching, 360 DF, ADCs, psychometric testing, Assessors programs etc.

D. Develop their diagnostic and OD skills and master at least some interventions.

E. Be prepared to work long term and for whole system change in any area of their work.

There are many studies on the competency models of OD professionals. (see Worley, Rothwell and Sullivan, 2005). A recent list provided by Worley et al (2005) will be of interest to the readers:

- Self-mastery

- Being comfortable with ambiguity

- Managing transitions and Institutionalization

- Participative create good implementation plan

- Managing separation

- Managing client ownership of change

- Setting conditions of positive change

- Using data to adjust change

- Ability to work with large systems

- Staying current with technology

- Ability to evaluate change

- Ability to clarify data needs

- Understand research methods

- Being available to listen to multiple stakeholders

- Building realistic relationships

- Ability to work with and manage diversity

- Ability to clarify roles

- Ability to work with power

- Ability to keep an open mind

- Ability to see whole picture

- Ability to integrate theory and practice

- Ability to focus on relevance and flexibility 
- Clarifying outcomes

Implied in this check list are the following competencies

- Self awareness

- Consulting process management competencies

- Ability to diagnose and understand the system, design and execute interventions, and work with large systems

- Ability to transfer knowledge to client

- Academic knowledge and skills in organizational behaviour, management and organization theory and specific knowledge and skills in OD

- Ability to stay current with technology

- Research methods competencies

- Interpersonal kills

- Systems thinking related competencies

- Integrating, balancing and applying theory and practice

\section{Conclusion:}

Rao and Rothwell (2005) have presented a case for bringing convergence and integrating HRM and OD though HRD audit. When India's (and perhaps the world's) first dedicated HRD department was conceptualized in L\&T in mid seventies OD was designed as a part of the HRD function. It was suggested that all HRD professionals should build OD competencies as internal change agents. HRD was conceived as change managing function and learning promotion function. In fact the First senior VP heading HR was designated as Senior VP Personnel and OD rather than an HRD and the Chief of HRD used to report to the VP Personnel and OD. At the same time the chief of HRD was required to have OD skills. (see Pareek and Rao, 1975). Even thirty five years after evolution of HRD, the importance of OD skills for HRD practitioner seems imminent as "Change" has become the order of the day and with fast rate of change required and ROI consciousness all over developing OD skills is a business imperative. 


\section{References}

1. Beckhard, R. (1969) Organization development: Strategies and Models, Reading, MA: Addison Wesley.

2. Bennis, W. (1969) Organization development: Its nature, origins and prospects. Reading, MA: Addison-Wesley.

3. Bradford, David L. (2005) Foreword to the book by: Rothwell, W. J. and Sullivan, Rolland (2005), Practicing Organization development: A Guide for Consultants Second edition, San Francisco, Pfeiffer, John Wiley and Sons.

4. Burke, W. W. (1982) Organization development: Principles and Practices, Boston: Mass.

5. French, W. L. and bell, C. H. Jr. (1999) Organization development: Behavioural Science Interventions for Organizational Improvement. Upper Saddle River, NJ: Prentice Hall.

6. McGovern, Joy, Michael Lindermann, Monica Vergara, Stacey Murphy, Linda barker and Rodney Warrenfeltz (2001) Maximizing the impact of Executive coaching: Behaviour change organizational outcomes and return on Investment, The Manchester Review, 2001, 6(1), 1-9

7. Pareek, Udai and Rao, T. V. (1975) Human Resources Development System in Larsen and Toubro, Ahmedabad: Indian Institute of Management, Consultancy report. Subsequently printed and published as "Pioneering Human Resources Development: The L\&T System, Ahmedabad: Academy of HRD, 1997.

8. Pareek, Udai, (1975)The concept and the process of Organization development, Indian Journal of Social work, 1975, 36(2), 109-125

9. Ramnarayan, S., Rao, T. V. and Kuldeep Singh. (1998) Organization development: Interventions and strategies, New Delhi, sage, 1998.

10. Rao, T. V and Rothwell, W.J. (2005) Using HRD audit to build Convergence between Human Resources development and Organization development, in Rothwell and Sullivan (2005 cited earlier.)

11. Rao, T. V. (2003) Future of HRD: New Delhi: Mac Milan.

12. Rao, T. V. (2004) Performance Management and Appraisal Systems: HR tools for global competitiveness; New Delhi: Sage- Response Books, 2004

13. Rao, T. V. (2008), Lessons of Experience: A New Look at Performance Management Systems, Vikalpa, 33(3), July-September 2008, 1-15.

14. Rothwell, W. J. and Sullivan, Rolland (2005), Practicing Organization Development: A Guide for Consultants, Second edition, San Francisco, Pfeiffer, John Wiley and Sons.

15. TVRLS (2006) Competency Mapping Education Kit, Ahmedabad, T. V. Rao Learning Systems, (www.tvrls.com)

16. Warrick, D. D. (2005) Organization development from the view of the Experts, in Rothwell, W J and Sullivan, Roland (cited below pages 164-186).

17. Worley, C. G, Rothwell, W J and Sullivan, Roland. (2005) Competencies of OD practitioners, in Rothwell and Sullivan (editors, cited earlier, 2005 pages 135-163) 